\title{
Competitive inhibition assay for the detection of progesterone in dairy milk using a fiber optic SPR biosensor
}

\author{
D. Daems ${ }^{\text {a }}$, J. Lu ${ }^{\text {a }}$, F. Delport ${ }^{\text {b }}$, N. Mariën ${ }^{\text {a }}$, L. Orbie ${ }^{\text {a }}$, B. Aernouts ${ }^{\text {c, d }}$, I. Adriaens ${ }^{\text {c }}$, \\ T. Huybrechts ${ }^{\text {c }}$, W. Saeys ${ }^{c}$, D. Spasic ${ }^{b}$, J. Lammertyn ${ }^{\mathrm{a},{ }^{*}}$ \\ a BIOSYST-MeBioS, KU Leuven, Willem de Croylaan 42, B-3001, Leuven, Belgium \\ ${ }^{\mathrm{b}}$ FOx Diagnostics BVBA, Temse, Belgium \\ ${ }^{\text {c } B I O S Y S T-M e B i o S, K U}$ Leuven, Kasteelpark Arenberg 30, B-3001, Leuven, Belgium \\ ${ }^{\mathrm{d}}$ Department of Microbial and Molecular Systems - Cluster for Bioengineering Technology, Campus Geel, KU Leuven, Kleinhoefstraat 4, B-2440, Geel, \\ Belgium
}

\section{H I G H L I G H T S}

- FO-SPR based competitive inhibition assay for detecting progesterone is described.

- A limit of detection of $0.5 \mathrm{ng} \mathrm{mL}^{-1}$ was achieved in 2-fold diluted bovine milk.

- Capacity for reducing the time-toresult was proven.

- The assay was evaluated with raw milk samples, showing excellent correlation with ELISA.

\section{A R T I C L E I N F O}

\section{Article history:}

Received 2 September 2016

Received in revised form

28 October 2016

Accepted 5 November 2016

Available online $\mathrm{xxx}$

\section{Keywords:}

Fiber optics

Surface plasmon resonance

Biosensor

Competitive inhibition assay

Progesterone

\section{G R A P H I C A L A B S T R A C T}

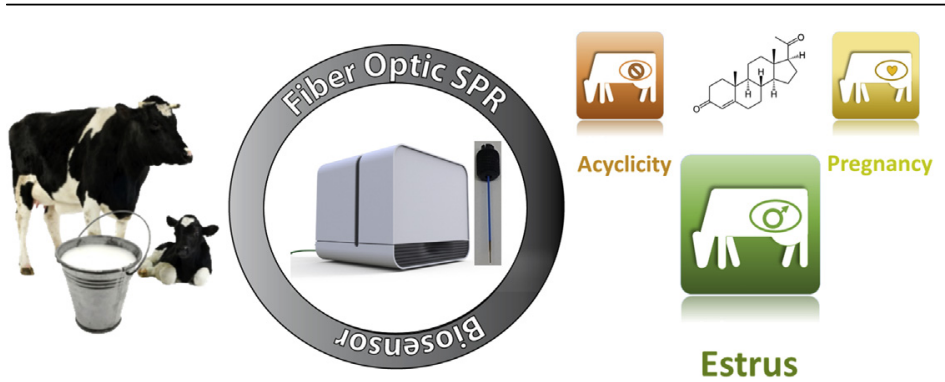

\begin{abstract}
A B S T R A C T
Analytical methods that are often used for the quantification of progesterone in bovine milk include immunoassays and chromatographic techniques. Depending on the selected method, the main disadvantages are the cost, time-to-result, labor intensity and usability as an automated at-line device. This paper reports for the first time on a robust and practical method to quantify small molecules, such as progesterone, in complex biological samples using an automated fiber optic surface plasmon resonance (FO-SPR) biosensor. A FO-SPR competitive inhibition assay was developed to determine biologically relevant concentrations of progesterone in bovine milk (1-10 ng/mL), after optimizing the immobilization of progesterone-bovine serum albumin (P4-BSA) conjugate, the specific detection with anti-progesterone antibody and the signal amplification with goat anti-mouse gold nanoparticles (GAM-Au NPs). The progesterone was detected in a bovine milk sample with minimal sample preparation, namely $1 / 2$ dilution of the sample. Furthermore, the developed bioassay was benchmarked against a commercially available ELISA, showing excellent agreement $\left(R^{2}=0.95\right)$. Therefore, it is concluded that the automated FO-SPR platform can combine the advantages of the different existing methods for quantification of progesterone: sensitivity, accuracy, cost, time-to-result and ease-of-use.
\end{abstract}

๑) 2016 Elsevier B.V. All rights reserved.

\footnotetext{
* Corresponding author.

E-mail address: jeroen.lammertyn@kuleuven.be (J. Lammertyn).
}

\section{Introduction}

In dairy industry, optimal reproductive performance of cows is a crucial factor for profitability [1,2]. In order to avoid long calving intervals and the related economic losses, accurate estrus detection 
is essential. However, not only do the modern high-productive dairy cows show their external estrous symptoms less clearly, the visual signs are also regularly missed due to the insufficient inspection of the cows on large farms. Therefore, in order to improve the detection of heat in dairy cows, one solution can be to use a biosensor for measuring hormone levels related to ovulation and heat, such as progesterone (P4), which is independent of the external symptoms [1-3]. The concentration of this important biomarker in milk correlates well with the level of this reproduction hormone in blood. The concentration of P4 is typically below $3.5 \mathrm{ng} \mathrm{mL} \mathrm{m}^{-1}$ in milk during estrus, while it is high for pregnant cows (>7 $\mathrm{ng} \mathrm{mL} \mathrm{m}^{-1}$ ) and remains high throughout gestation [1,4]. Hence, regular monitoring of milk $\mathrm{P} 4$ levels is very useful for dairy farmers to accurately identify cows in heat and optimize the timing of artificial insemination as well as to detect pregnancy in an early stage or abnormalities in the estrous cycle $[3,5]$.

Standard analytical techniques frequently used in the past for P4 monitoring, like thin layer chromatography and gas chromatography [6], isotope dilution in combination with mass spectrometry [7] and high performance liquid chromatography [8,9] suffered from a number of drawbacks such as high costs, extensive sample preparation and their limitation to be only used in a lab environment. More recently, sensitive bio-analytical methods based on immunologic concepts were developed and commercialized [10,11]: radioimmunoassays (RIA) [12], lateral flow immunoassays (LFI) [13,14], fluorescence immunoassays (FIA) [15,16], electrochemical immunosensors [17], and enzyme immunoassays (EIA) $[1,10,18,19]$. The advantages of these methods are mainly their specificity and sensitivity in the targeted concentration range (1-10 ng mL ${ }^{-1}$ ) [13]. Among these, the two most commonly used are ELISA and lateral flow tests, which have both been shown to provide reliable measurement results for $\mathrm{P} 4$ detection with minimal sample preparation. The major drawbacks of the reference ELISA tests are the time-to-result $(\geq 1 \mathrm{~h})$ and the laborious handling steps $[1,2,20]$. On the other hand, the sensitivity of the fast ( $\leq 15 \mathrm{~min}$ ) lateral flow tests $(0.8-5 \mathrm{ng} / \mathrm{mL}[13,14,21])$ is considerably lower than that of ELISA $(0.2-1.3 \mathrm{ng} / \mathrm{mL}[1,20])$. Despite these disadvantages this lateral flow technology is already used in dairy farming for monitoring the reproductive status of a cow by means of an automated online tool, called the Herd Navigator (Lattec, Hillerød, Denmark) [3,22].

Immunoassays for P4 detection can also be implemented on a surface plasmon resonance (SPR) based transduction platform [23]. SPR is an advanced label-free, real-time detection technology that provides accurate information on analyte concentrations and binding kinetics $[24,25]$. Although SPR is already widely used to detect proteins, peptides and nucleic acids, monitoring small molecules still remains challenging [5], as their direct binding to the sensor surface results in a weak signal $[5,26]$.

In this work, the use of one such SPR platform, being an in-house developed fiber optic (FO)-SPR, is demonstrated for the first time for the detection of low molecular weight targets. This FO-SPR sensor platform has been previously reported as a cost-effective and easy to use alternative to the expensive and more complex SPR systems [27] for (i) studying the binding kinetics of bacteriophages on the sensor surface [28], (ii) the implementation of antibody and aptamer based assays on the fiber surface [29-31], and (iii) the implementation of DNA/RNA based assays including the real time monitoring of nucleic acid amplification and highresolution melting for single nucleotide polymorphism detection [27,32-34]. Here, the development of a competitive inhibition bioassay for detection of P4 in bovine milk samples (Fig. 1) on the FO-SPR platform (ciFO-SPR) is described. In the ciFO-SPR, a detection antibody competes to bind either P4 from the sample or its derivative immobilized on the sensor surface. To improve the limit of detection (LOD), the signal is amplified by means of gold nanoparticles (Au NPs) functionalized with a goat anti-mouse antibody (GAM), similar to other competitive immunoassays for small molecules $[5,24,26]$. The established ciFO-SPR is validated against a competitive commercially available ELISA (cELISA).

\section{Materials and methods}

\subsection{Reagents}

All chemicals were of analytical reagent grade. Progesterone (P4) and buffer reagents were supplied by Sigma-Aldrich (Belgium), unless stated otherwise. Solutions were prepared with deionized water purified by a Milli-Q Plus system (Millipore, Marlborough, MA, USA). Acetic acid, hydrochloric acid and sodium hydroxide were purchased from Chem-Lab (Belgium). Sodium chloride, 1ethyl-3-(3-dimethylaminopropyl) carbodiimide (EDC) and $\mathrm{N}$ hydroxysuccinimide (NHS) were supplied by Fischer Scientific (Belgium) and Tween-20 by Applichem (Germany). ProgesteroneBSA conjugate (P4-BSA) and mouse anti-progesterone antibody (anti-P4 Ab) were purchased from AbD Serotec (UK). Goat antimouse antibody (GAM Ab) was supplied by Life Technologies (Belgium). Au NPs (ø $20 \mathrm{~nm}$ ) were produced by BBI Solutions (UK) and carboxylic acid-SAM formation reagent was purchased from Dojindo (Japan). The milk progesterone enzyme-immunoassay (Mkit Elisa) and ELISA milk standards were purchased from Ridgeway Science (UK). A milk sample was collected for 6 cow (numbered Cow 1-6) selected from a 50 headed herd on an experimental farm (Hooibeekhoeve, Geel) in Flanders, Belgium. These samples were taken from cows in heat.

\subsection{FO-SPR setup}

The FO-SPR device and FO-SPR sensor tips were manufactured as previously described in detail [27,32]. In short, the FO-SPR device consists of a HL-FHSA tungsten halogen lamp (Ocean optics, USA), a UV-VIS spectrophotometer (USB4000, Ocean Optics, USA) and a FOSPR sensor tip. All the components were installed on a High-Z S400 $\mathrm{CNC}$ T router (CNC-Step, Germany) to allow automated handling. A modified T1 thermocycler (Biometra, Germany) was used to control the temperature of the samples. The replaceable FO-SPR sensor tips were coupled by means of an SMA-type connector to a bifurcated optical FO-SPR sensor to guide white light from the halogen lamp into the FO-SPR sensor tip, and back to the spectrophotometer $[32,33]$. Binding phenomena at the gold surface of the sensor tip result in a shift of the typical spectral resonance SPR-dip recorded by the spectrophotometer.

The manufacturing of a FO-SPR sensor tip consisted of several steps. Briefly, the jacket and the cladding of a $400 \mu \mathrm{m}$ multimode TEQS fiber (Thorlabs, Germany) were respectively removed with pliers and acetone. Subsequently, the fiber was cleaved with a LDC400 device (Vytran, UK) to make a FO-SPR sensor with a total length of $4.3 \mathrm{~cm}$ (a middle part with cladding of $3.6 \mathrm{~cm}$ and two ends of $0.6 \mathrm{~cm}$ and $0.1 \mathrm{~cm}$ ). Next, a $50 \mathrm{~nm}$ gold coating was deposited onto the $0.6 \mathrm{~cm}$ end of the FO-SPR sensor surface using a sputter coater (Quorum Q150T ES, UK). The freshly prepared FO-SPR sensor tips were incubated overnight with a $100 \mu \mathrm{M}$ mixed self-assembling monolayer (Carboxylic acid-SAM formation reagent), washed in ethanol, and stored in $50 \mathrm{mM}$ MES buffer ( $\mathrm{pH} \mathrm{6)}$ until further use.

\subsection{Immobilization of goat anti-mouse antibody on gold nanoparticles}

GAM Ab was coupled to Au NPs (ø $20 \mathrm{~nm}$ ) by passive adsorption. First, the $\mathrm{pH}$ of the Au NPs (initial concentration of $7 \times 10^{11}$ particles 


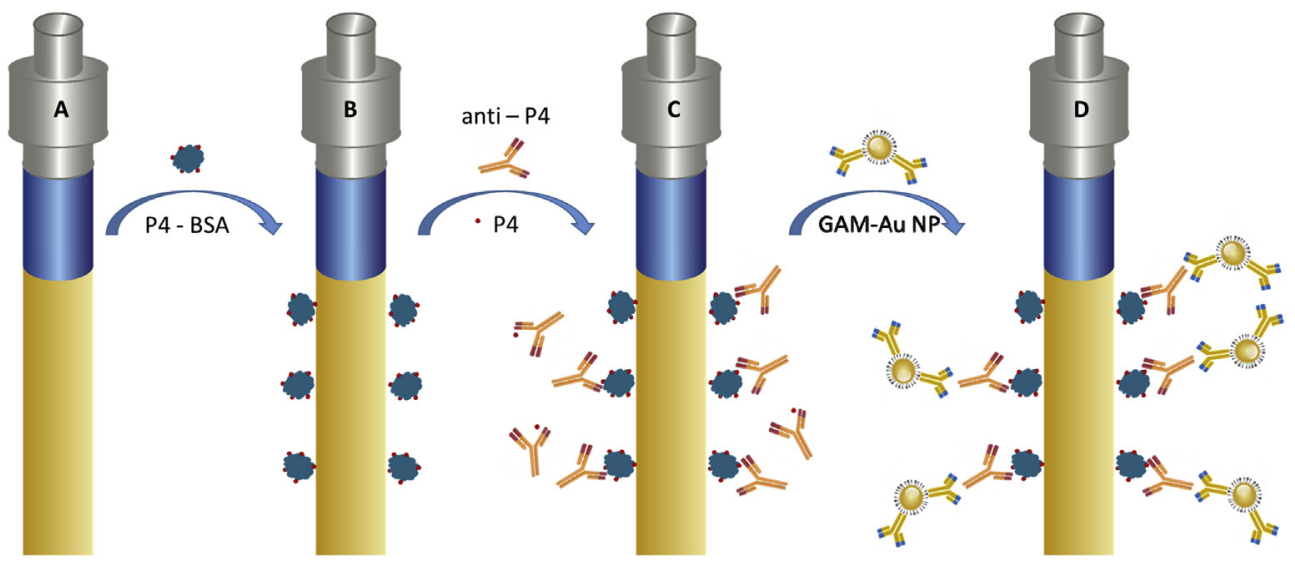

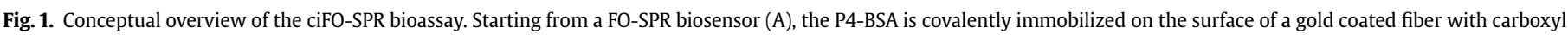

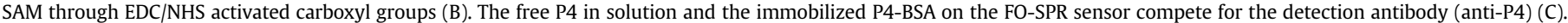
The signal is enhanced by Au NPs functionalized with GAM-Au NPs (D).

per $\mathrm{mL}$ ) was adjusted to $\mathrm{pH} 9.2$ with a $0.2 \mathrm{M} \mathrm{Na}_{2} \mathrm{CO}_{3}$ solution. Following, the GAM Abs were added to the Au NPs at final concentration of $5 \mu \mathrm{g} / \mathrm{mL}$ and incubated on a rotator (Grant-Bio PRT-30, Keison products, UK) at room temperature for $20 \mathrm{~min}$. In a next step, $500 \mu \mathrm{l}$ of $0.5 \%$ BSA in PBS was added to the Au NPs and incubated on the rotator for $1 \mathrm{~h}$ to reduce unspecific binding of the Au NPs to the FO-SPR sensor tip during detection. After centrifugation of the Au NP-solution for $40 \mathrm{~min}$ at $7000 \mathrm{rpm}$ at $20^{\circ} \mathrm{C}$, the supernatant was discarded and the GAM-Au NPs were diluted in PBS buffer to a final optical density (OD) of 0.5 or 1.0 (wavelength $=530 \mathrm{~nm}$ ), corresponding to the concentration of $7 \times 10^{11}$ or $14 \times 10^{11} \mathrm{Au}$ NPs per $\mathrm{mL}$, respectively. The OD was measured with a SpectraMax M2 spectrophotometer (Molecular Devices LLC., USA). The prepared Au NPs were stored at $4{ }^{\circ} \mathrm{C}$ until use.

\subsection{Competitive inhibition assay on the FO-SPR}

The FO-SPR sensor tip was immersed in $50 \mathrm{mM}$ MES buffer to reach a stable baseline, followed by activation of the carboxyl groups on the FO-SPR sensor tip surface using $150 \mu \mathrm{L}$ of $0.4 \mathrm{M}$ EDC and $0.1 \mathrm{M}$ NHS in $50 \mathrm{mM}$ MES solution for $10 \mathrm{~min}$. Next, the FO-SPR sensor tip was immersed in the P4-BSA conjugate solution with a concentration of 25,50 or $100 \mu \mathrm{g} \mathrm{mL}^{-1}$ in $10 \mathrm{mM}$ sodium acetate (pH 4.5) for $30 \mathrm{~min}$, followed by a short washing step of $30 \mathrm{~s}$ in a regeneration buffer ( $1 \mathrm{M} \mathrm{NaCl}$ and $50 \mathrm{mM} \mathrm{NaOH})$. The unreacted activated groups were blocked with $150 \mu \mathrm{L}$ of $50 \mathrm{mM}$ ethanolamine in PBS for 8 min.

In the first step of the ciFO-SPR bioassay, the P4-BSA functionalized FO-SPR sensor tip was put in $150 \mu \mathrm{L}$ of a pre-incubated mixture of anti-P4 Ab in PBS buffer with $0.5 \%$ BSA and (i) a P4 dilution in PBS or (ii) a milk sample for 15 min. Milk standards and bovine milk samples were incubated for $10 \mathrm{~min}$ at $37^{\circ} \mathrm{C}$ and vortexed before use. Next, the signal of the anti-P4 Abs, captured onto the P4-BSA sensor tip surface, was amplified for $30 \mathrm{~min}$ by binding with the GAM-Au NPs. The complete protocol for detecting P4 is shown in Supplementary Information Table S-1.

\subsection{ELISA procedure}

A commercially available competitive ELISA (M-Kit, cELISA) was applied as a reference technology for P4 quantification in bovine milk samples in this study. The wells of a microtiter plate were loaded with either $10 \mu \mathrm{L}$ of milk standard or sample solution. These milk standards were derived from an anoestrus or ovariectomized cow in which there will be little or negligible amounts of $\mathrm{P} 4$ and spiked with P4 (0-10 ng mL $\left.{ }^{-1}\right)$. Following, $200 \mu \mathrm{L}$ of progesterone labeled enzyme was added to each well and incubated for $1 \mathrm{~h}$ at room temperature. The microtiter plate was washed 3 times with $200 \mu \mathrm{L}$ cold demi-water $\left(5^{\circ} \mathrm{C}\right)$. Finally, $200 \mu \mathrm{L}$ of the substrate solution was added to each well and after $20 \mathrm{~min}$ the color change was quantified in terms of the absorption at $570 \mathrm{~nm}$ as measured with a spectrophotometer (SpectraMax M2, Molecular Devices LLC., USA).

\subsection{Data processing}

FO-SPR data were recorded with LabView (National Instruments, USA) and further processed using Origin 8 (OriginLab, USA). Calibration curves were fitted with a logistic fit [35]:

$y=A_{2}+\frac{\left(A_{1}-A_{2}\right)}{1+\left(\frac{x}{x_{0}}\right)^{p}}$

where $A_{1}$ is the minimum asymptote (response value at zero standard concentration), $A_{2}$ is the maximum asymptote (response value for infinite standard concentration), $x$ is the target concentration, $x_{0}$ is the inflection point, $p$ is the Hill's slope (refers to the steepness of the curve), and $y$ is the FO-SPR shift.

Equation (2) was used to calculate the LOD of the established bioassays:

$L O D x=x_{0} \times \sqrt[p]{\frac{\left(A_{1}-A_{2}\right)}{\left(\left(L O D Y-A_{2}\right)-1\right)}}$

where LOD $y=y_{0}-3 \times s_{0}$, with $y_{0}$ is the average response for $0 \mathrm{ng} /$ $\mathrm{mL} \mathrm{P} 4$ and $s_{0}$ is the mean standard deviation for $y_{0}$.

The intraclass correlation coefficient (ICC) [36], which assesses the reliability of ratings by comparing the variability of different ratings of the same object, was calculated with the statistical package $\mathrm{R}$ (version 2.11.1, The $\mathrm{R}$ foundation for Statistical Computing, Vienna, Austria).

\section{Results and discussion}

\subsection{FO-SPR competitive inhibition assay development}

A competitive inhibition bioassay was implemented on the FO- 
A

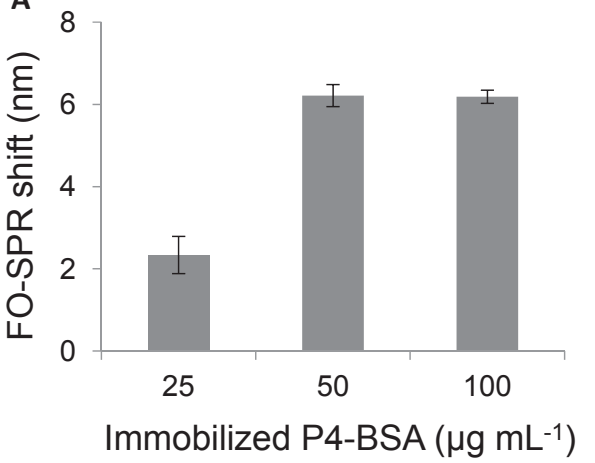

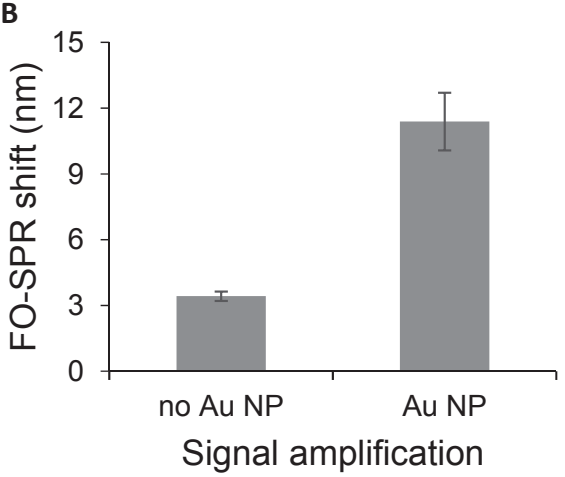

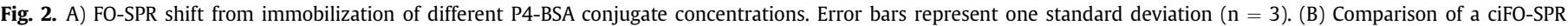
bioassay using anti-P4 Ab with or without Au NPs for signal amplification as detection antibody. Error bars represent one standard deviation ( $\mathrm{n}=3$ ).

SPR to quantify the concentration of P4 in milk samples. This type of bioassay was chosen since for low molecular weight targets the sensitivity of SPR based sensors is often not adequate. As indicated in Fig. 1, the free P4 in solution and the P4-BSA conjugate immobilized on the FO-SPR sensor tip surface get in competition for the detection antibody (anti-p4). To improve the LOD, the signal generated by the binding of the detection antibody to the FO-SPR sensor tip was amplified through the binding of Au NPs functionalized with GAM antibody (GAM-Au NP) (Figure S-1). In order to achieve a reproducible calibration curve for the ciFO-SPR bioassay, three main aspects of the assay were first optimized in buffer conditions: (i) immobilization of P4-BSA conjugate to the FO-SPR sensor tip surface, (ii) signal amplification by GAM-Au NPs and (iii) specific detection by monoclonal anti-P4 Ab. These parameters were evaluated based on the size of the FO-SPR shift, reproducibility, sensitivity, and LOD.

Firstly, the FO-SPR sensor tip was functionalized with three different P4-BSA concentrations (25, 50 and $100 \mu \mathrm{g} / \mathrm{mL}$ ) (Fig. 2A). The immobilization with both 50 and $100 \mu \mathrm{g} \mathrm{mL}^{-1}$ P4-BSA conjugate resulted in the highest and most reproducible FO-SPR shifts with coefficients of variation (CV) below $5 \%$. In order to minimize the cost of the bioassay, $50 \mu \mathrm{g} \mathrm{mL}^{-1}$ was selected for immobilization, unless stated otherwise. To quantify the level of aspecific binding, tests were performed in absence of the P4-BSA conjugate on the FO-SPR sensor tip surface. This resulted in a negligible shift of $0.06 \mathrm{~nm}$ with a CV of $2.4 \%$ (data not shown). Moreover, the antiP4 Ab was specific for P4 as no significant FO-SPR shift was observed when BSA without P4 was immobilized on the FO-SPR sensor tip surface (data not shown).
Secondly, the role of Au NPs on the signal amplification was studied by comparing the direct binding of free anti-P4 Ab to the FO-SPR sensor tip surface and the same antibody when functionalized to Au NPs. In both cases, the FO-SPR sensor tip surface was functionalized with a $100 \mu \mathrm{g} \mathrm{mL}^{-1}$ P4-BSA conjugate. A 3.3 times increase in FO-SPR shift was obtained when anti-P4 Ab was immobilized on Au NPs ( $11 \pm 1 \mathrm{~nm}, \mathrm{n}=3)$ compared to free anti-P4 $\mathrm{Ab}(3.4 \pm 0.2 \mathrm{~nm}, \mathrm{n}=3$ ) (Fig. $2 \mathrm{~B}$ ). Moreover, it was also observed that the concentration of Au NPs plays an important role in the signal amplification efficiency. By doubling the initial concentration of GAM-Au NPs from 0.5 to 1 OD in the ciFO-SPR bioassay, the FO-SPR shift was doubled after 30 min (Figure S-2). Importantly, both for bare Au NPs and GAM-Au NPs, interaction with BSA and P4-BSA conjugate immobilized on the FO-SPR sensor tip surface resulted in negligible FO-SPR shifts, proving there is no aspecific binding (data not shown).

Thirdly, the influence of the anti-P4 Ab concentration on the shape of the calibration curve, and correspondingly the LOD, was studied. Four different concentrations of anti-P4 Ab were tested in buffer conditions: $0.1,0.2,0.4$ and $0.8 \mu \mathrm{g} \mathrm{mL} \mathrm{m}^{-1}$. For the first two conditions, GAM-Au NP concentration was doubled (from $7 \times 10^{11}$ to $14 \times 10^{11} \mathrm{Au}$ NPs per $\mathrm{mL}$ ) to accelerate binding kinetics. The FOSPR shifts obtained from different anti-P4 Ab concentrations were plotted as a function of the P4 concentrations $(0,1,2,5$, and $10 \mathrm{ng} \mathrm{mL} \mathrm{m}^{-1}$ ). A logistic fit (Eqn. (1)) was used to establish the calibration curves (Figure S-3). The steepness of the calibration curves ( $p$-value from Eqn. (1)) was used as a criterion for the sensitivity of the bioassay, with steeper calibration curves having lower $p$-value. Thus, the $p$-value decreased from $2.0 \pm 0.6 \mathrm{~nm}$ for
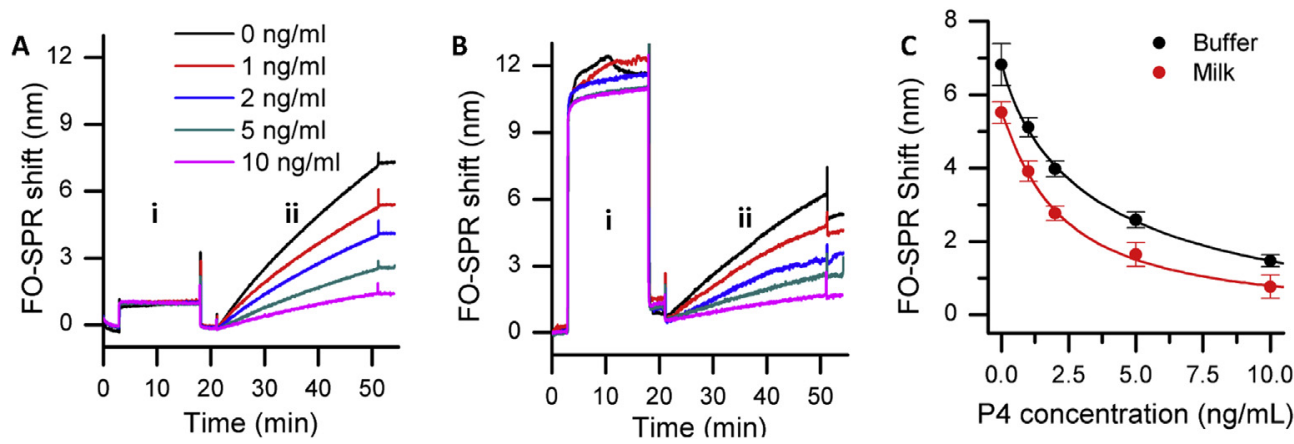

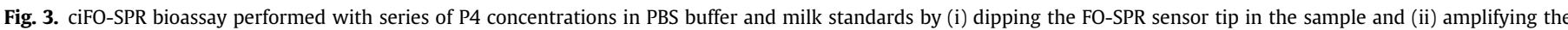

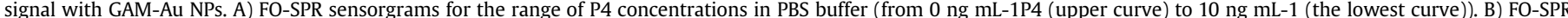

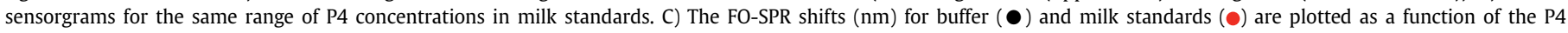
concentrations, yielding a logistic fit calibration curve (based on Eqn. (1)). Error bars represent one standard deviation ( $\mathrm{n}=4$ in buffer and $\mathrm{n}=3$ in milk standards). 


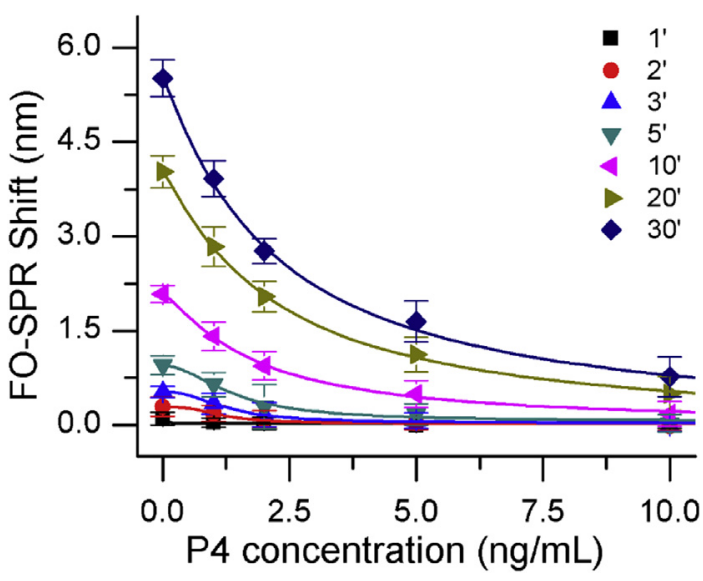

Fig. 4. Calibration curves for $\mathrm{P} 4$ established with different duration of the signal amplification step $(1,2,3,5,10,20$ and $30 \mathrm{~min})$. Error bars represent one standard deviation $(\mathrm{n}=3)$.

$0.8 \mu \mathrm{g} \mathrm{mL}{ }^{-1}$ anti-P4 Ab to $1.1 \pm 0.2$ for $0.1 \mu \mathrm{g} \mathrm{mL}^{-1}$ anti-P4, resulting in a more sensitive calibration curve. Correspondingly, the LOD decreased from $5.7 \mathrm{ng} \mathrm{mL}^{-1}$ to $0.7 \mathrm{ng} \mathrm{mL}^{-1}$ of P4. Moreover, the CV was the lowest for 0.1 and $0.2 \mu \mathrm{g} \mathrm{mL}^{-1}$ of detection $\mathrm{Ab}$, namely $9 \%$. In conclusion, the lowest anti-P4 Ab concentration $\left(0.1 \mu \mathrm{g} \mathrm{mL}^{-1}\right)$ showed the best reproducibility, highest sensitivity and lowest LOD (Table S-2).

\subsection{Progesterone detection in buffer and milk standards with ciFO- SPR assay}

Using the optimized parameters of the ciFO-SPR bioassay, a calibration curve was established for measurement of P4 concentrations in the range of $1-10 \mathrm{ng} \mathrm{mL} L^{-1}$ in PBS buffer and milk standards (Fig. 3C), starting from their FO-SPR sensorgrams (Fig. 3A and B). Although the signal amplification step with GAMAu NPs was $30 \mathrm{~min}$ in both cases, the FO-SPR shift was higher for buffer compared to the milk samples. This difference can be explained by the change in refractive index (RI) induced by dipping the FO-SPR biosensor tip in a milk sample. However, the overall $\Delta R I$ [37], between PBS buffer before and after the dipping step, is similar for experiments in buffer and milk. This observation indicated that no milk residues are sticking to the FO-SPR sensor tip. In Fig. 3C, a logistic curve (Eqn. (1)) was fitted on the

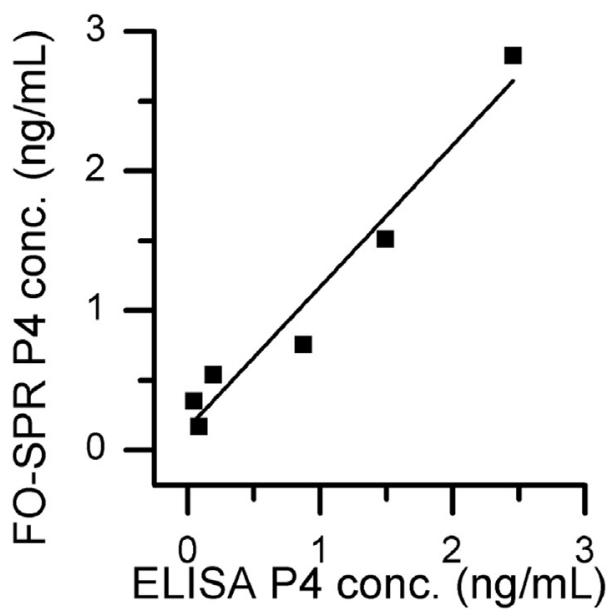

Fig. 5. Comparison of the P4 levels determined with the in-house developed ciFO-SPR biosensor and the commercial cELISA test. measurements for both buffer $\left(\mathrm{R}^{2}=0.99, \mathrm{n}=4\right)$ and milk standards $\left(\mathrm{R}^{2}=0.99, \mathrm{n}=3\right)$, resulting in LOD values of 0.6 and $0.5 \mathrm{ng} /$ $\mathrm{mL}$ and CVs of 8 and 16\%, respectively. Furthermore, zooming into the most relevant concentration range $\left(0-5 \mathrm{ng} \mathrm{mL} \mathrm{m}^{-1}\right)$, linked to the heat in cows, decreased the average variation both for buffer samples (7\%) and for milk standards (9\%). As the steepness was maximized over the most important interval of the ciFO-SPR calibration curve, the signal variation of the higher P4 concentrations is increased using the logistic fit. In the remainder of this paper, the calibration curve for milk will be used to determine the P4 concentrations in raw bovine milk samples with the FO-SPR sensor.

The potential of the FO-SPR platform as a field device with limited sample preparation was further explored by shortening the measurement time of the established ciFO-SPR bioassay. Besides the functionalization of the FO-SPR sensor tip, which can be done in advance, the signal amplification with GAM-Au NPs is the most time consuming step, being $30 \mathrm{~min}$ in the presented bioassay. Therefore, the effect of shortening this amplification step on the calibration curve was evaluated based on reproducibility, sensitivity and LOD (Fig. 4). The experiment was performed on milk standards with various duration of the amplification step, ranging from 1 to $30 \mathrm{~min}$. The steepness of the calibration curves ( $p$-value Eqn. (1)) was again used as a criterion for sensitivity. The $p$-value was similar for signal amplification during $10 \min (1.3 \pm 0.2 \mathrm{~nm})$, $20 \min (1.1 \pm 0.1 \mathrm{~nm})$ and $30 \mathrm{~min}(1.1 \pm 0.2 \mathrm{~nm})$, resulting in a similar sensitivity. Moreover, based on Eqn. (2), similar LODs were obtained for these bioassays: $0.6 \mathrm{ng} \mathrm{\textrm {mL } ^ { - 1 }}$ for 10 and $20 \mathrm{~min}$ and $0.5 \mathrm{ng} \mathrm{mL}-1$ for $30 \mathrm{~min}$. However, the average $\mathrm{CV}$ over the $\mathrm{P} 4$ concentration range $0-5 \mathrm{ng} \mathrm{mL}^{-1}$ increased from $9 \%$ (30 min, $\left.\mathrm{R}^{2}=0.99\right)$ to $14 \%\left(20 \mathrm{~min}, \mathrm{R}^{2}=0.99\right)$ and $22 \%\left(10 \mathrm{~min}, \mathrm{R}^{2}=0.99\right)$. Further decrease in time affected the quality of the fit $\left(\mathrm{R}^{2}<0.99\right)$, the reproducibility $(\mathrm{CV}>25 \%)$, the sensitivity ( $p$-value $\geq 2 \mathrm{~nm}$ ) and the LOD ( $>1.3 \mathrm{ng} / \mathrm{mL})$. In conclusion, combining independent prefunctionalization of the FO-SPR sensor tip with a signal amplification step of 10 min can bring the total detection time under $20 \mathrm{~min}$, offering the possibility to determine the P4 concentration in raw milk shortly after the milking of a cow.

\subsection{Screening of biological samples}

The established ciFO-SPR bioassay for quantification of P4 in milk was further validated against the cELISA, the most commonly used method for P4 quantification in milk, by measuring six bovine milk samples taken from six different cows. These samples were taken from cows in heat, thus typically having a low P4 level (<3.5 ng $\mathrm{mL}^{-1}$ ). The samples were processed with a minimal sample preparation procedure consisting of two steps: (i) incubating for $10 \mathrm{~min}$ at $37^{\circ} \mathrm{C}$ and (ii) diluting the sample with anti-P4 $\mathrm{Ab}$ in buffer (Section 2.4). The P4 concentrations in the six bovine samples were determined with the ciFO-SPR biosensor using the calibration curve in milk standards shown in Fig. 3C. All the values obtained for the FO-SPR shifts ( $\mathrm{nm}$ ) and the ELISA absorbance signals (AU) are shown for each sample in Figure S-4. The average CV was $14 \%$ and $22 \%$ for ciFO-SPR $(n=4)$ and cELISA $(n=6)$, respectively. As shown in Fig. 5, the P4 concentrations quantified with the ciFO-SPR bioassay correlated linearly with the corresponding cELISA results $\left(\mathrm{R}^{2}=0.95\right)$. Moreover, the ICC was calculated to be $0.97(n=6)$.

\section{Conclusions}

Despite advances in accuracy and time-to-result, off-laboratory screening of P4 with automated and cost-effective assays is still a challenging. In search of new techniques to quantify P4 in bovine 
milk, an in-house developed FO-SPR biosensor was explored for establishing a competitive inhibition bioassay. The designed ciFOSPR bioassay was first optimized by determining the concentration of (i) P4-BSA conjugate to be immobilized on the FO-SPR sensor tip, (ii) anti-P4 antibody and (iii) GAM-Au NPs. Calibration curves were established with the ciFO-SPR bioassay for spiked buffer samples and milk standards in the biologically relevant concentration range between 1 and $10 \mathrm{ng} \mathrm{mL}^{-1}$, resulting in an LOD of $0.6 \mathrm{ng} \mathrm{mL} \mathrm{m}^{-1}$ and $0.5 \mathrm{ng} \mathrm{mL}^{-1} \mathrm{P} 4$, respectively. Furthermore, the time-to-result of the established ciFO-SPR bioassay was reduced under 20 min resulting in a similar LOD and sensitivity of the assay. Finally, the bioassay was validated against a reference cELISA technique. In the low concentration range corresponding to heat, the results obtained with the ciFO-SPR biosensor for bovine milk samples correlated very well with those of the cELISA, resulting in ICC of 0.97. In conclusion, the developed platform combines the ease-of-use and cost efficiency of a lateral flow assay with the accuracy, sensitivity and possibility for automation of an ELISA test. Future work will focus on integrating this ciFO-SPR bioassay in an automated milking robot on a dairy farm to monitor the reproductive cycle of dairy cows.

\section{Acknowledgements}

We gratefully acknowledge financial support from KU Leuven (IOF/KP/12/002-Nanodiag; PDM/15/111 Devin Daems), and the Institute for the Promotion of Innovation through Science and Technology in Flanders (IWT-Flanders) for the financial support through the projects Sensors for Food (100936) and Koesensor (110770). . Tjebbe Huybrechts is funded by the Agency for Innovation by Science and Technology, Flanders (IWT-Flanders 121611). Ines Adriaens and Ben Aernouts are supported by the Fund for Scientific Research (FWO-Flanders 11ZG916N and 12K3916N respectively).

\section{Appendix A. Supplementary data}

Supplementary data related to this article can be found at http:// dx.doi.org/10.1016/j.aca.2016.11.005.

\section{References}

[1] R. Claycomb, M.J. Delwiche, C.J. Munro, R.H. BonDurant, Rapid enzyme immunoassay for measurement of bovine progesterone, Biosens. Bioelectron. 13 (1998) 1165-1171.

[2] R. Simersky, J. Swaczynova, D.A. Morris, M. Franek, M. Strnad, Development of an ELISA-based kit for the on-farm determination of progesterone in milk, Vet. Med. 52 (2007) 19-28.

[3] N.C. Friggens, M.G. Chagunda, Prediction of the reproductive status of cattle on the basis of milk progesterone measures: model description, Theriogenology 64 (2005) 155-190.

[4] A. Chanvallon, S. Coyral-Castel, J. Gatien, J.-M. Lamy, D. Ribaud, C. Allain, P. Clément, P. Salvetti, Comparison of three devices for the automated detection of estrus in dairy cows, Theriogenology 82 (2014) 734-741.

[5] J. Mitchell, Small molecule immunosensing using surface plasmon resonance, Sensors 10 (2010) 7323-7346.

[6] J.A.B. Darling, A.H. Laing, R.A. Harkness, A survey of the steroids in cows' milk, J. Endocrinol. 62 (1974) 291-297.

[7] L. Siekmann, Determination of steroid hormones by the use of isotope dilution-mass spectrometry: a definitive method in clinical chemistry, J. Steroid Biochem. 11 (1979) 117-123.

[8] R.H. Purdy, C.K. Durocher, P.H. Moore, P. Narasimha Rao, Analysis of metabolites of progesterone in bovine liver, kidney, kidney fat, and milk by high performance liquid chromatography, J. Steroid Biochem. 13 (1980) 1307-1315.

[9] M.S. Díaz-Cruz, M.J. López de Alda, R. López, D. Barceló, Determination of estrogens and progestogens by mass spectrometric techniques (GC/MS, LC/MS and LC/MS/MS), J. Mass Spectrom. 38 (2003) 917-923.
[10] T. Ivanova, T. Godjevargova, Sensitive progesterone determination using a magnetic particle-based enzyme-linked immunosorbent assay, Anal. Lett. 48 (2015) 843-860.

[11] R.L. Nebel, D.L. Altemose, T.W. Munkittrick, D.J. Sprecher, M.L. McGilliard, Comparisons of eight commercial on-farm milk progesterone tests, Theriogenology 31 (1989) 753-764.

[12] G.A. Posthuma-Trumpie, A. van Amerongen, J. Korf, W.J.H. van Berkel, Perspectives for on-site monitoring of progesterone, Trends Biotechnol. 27 (2009) 652-660.

[13] J.V. Samsonova, V.A. Safronova, A.P. Osipov, Pretreatment-free lateral flow enzyme immunoassay for progesterone detection in whole cows' milk, Talanta 132 (2015) 685-689.

[14] M.P.A. Laitinen, M. Vuento, Immunochromatographic assay for quantification of milk progesterone, Acta Chem. Scand. 50 (1996) 141-145.

[15] N.D. Käppel, F. Pröll, G. Gauglitz, Development of a TIRF-based biosensor for sensitive detection of progesterone in bove milk, Biosens. Bioelectron. 22 (2007) 2295-2300.

[16] L. Trapiella-Alfonso, J.M. Costa-Fernández, R. Pereiro, A. Sanz-Medel, Development of a quantum dot-based fluorescent immunoassay for progesterone determination in bovine milk, Biosens. Bioelectron. 26 (2011) 4753-4759.

[17] H.Y. Zhang, X.Y. Du, Q. Liu, C. Xia, L.W. Sun, Detection of progesterone in bovine milk using an electrochemical immunosensor, Int. J. Dairy Technol. 66 (2013) 461-467.

[18] T. Van der Lende, R.B.M. Schasfoort, R.F. van er Meer, Monitoring reproduction using immunological techniques, Anim. Reprod. Sci. 28 (1992) 179-185.

[19] L. Wu, C. Xu, C. Xia, Y. Duan, C. Xu, H. Zhang, J. Bao, Development and application of an ELISA kit for the detection of milk progesterone in dairy cows, Monoclon. Antib. Immunodiagn. Immunother. 33 (2014) 330-333.

[20] D.F.M. van de Wiel, W. Koops, Development and validation of an enzyme immunoassay for progesterone in bovine milk or blood plasma, Anim. Reprod. Sci. 10 (1986) 201-213.

[21] K. Sananikone, M.J. Delwiche, R.H. BonDurant, C.J. Munro, Quantitative lateral flow immunoassay for measuring progesterone in bovine milk, T ASAE 47 (2004) 1357-1365.

[22] A. Waldmann, A. Raud, Comparison of a lateral flow milk progesterone test with enzyme immunoassay as an aid for reproductive status determination in cows, Veterinary Rec. (2016), http://dx.doi.org/10.1136/vr.103605.

[23] E.H. Gillis, I. Traynor, J.P. Gosling, M. Kane, Improvements to a surface plasmon resonance-based immunoassay for the steroid hormone progesterone, J. AOAC 89 (2006) 838-842.

[24] R.B.M. Schasfoort, A.J. Tudos, Handbook of Surface Plasmon Resonance, Royal Society of Chemistry, Cambridge, U.K, 2008.

[25] J. Homola, Surface plasmon resonance sensors for detection of chemical and biological species, Chem. Rev. 108 (2008) 462-493.

[26] J. Homola, S. Yee, G. Gauglitz, Surface plasmon resonance sensors: review, Sensors Actuators B Chem. 54 (1999) 3-15.

[27] J. Pollet, K.P.F. Janssen, K. Knez, J. Lammertyn, Real-time monitoring of solidphase PCR using fiber-optic SPR, Small 7 (2011) 1003-1006.

[28] K. Knez, W. Noppe, N. Geukens, K.P.F. Janssen, D. Spasic, J. Heyligen, K. Vriens K. Thevissen, B.P.A. Cammue, V. Petrenko, C. Ulens, H. Deckmyn, J. Lammertyn, Affinity comparison of $\mathrm{p} 3$ and $\mathrm{p} 8$ peptide displaying bacteriophages using surface plasmon resonance, Anal. Chem. 85 (2013) 10075-10082.

[29] J. Lu, T. Van Stappen, D. Spasic, F. Delport, S. Vermeire, A. Gils, J. Lammertyn, Fiber optic-SPR platform for fast and sensitive infliximab detection in serum of inflammatory bowel disease patients, Biosens. Bioelectron. 79 (2016) 173-179.

[30] J. Pollet, F. Delport, K.P.F. Janssen, D.T. Tran, J. Wouters, T. Verbiest, J. Lammertyn, Dast and accurate peanut allergen detection with nanobead enhanced optical fiber SPR biosensor, Talanta 83 (2011) 1436-1441.

[31] D.T. Tran, K. Knez, K.P.F. Janssen, J. Pollet, D. Spasic, J. Lammertyn, Selection of aptamers against Ara h 1 protein for FO-SPR biosensing of peanut allergens in food matrices, Biosens. Bioelectron. 43 (2013) 245-251.

[32] K. Knez, K.P.F. Janssen, J. Pollet, D. Spasic, J. Lammertyn, Fiber-optic highresolution genetic screening using gold-labeled gene probes, Small 8 (2012) $868-872$.

[33] K. Knez, K.P.F. Janssen, D. Spasic, P. Declerck, L. Vanysacker, C. Denis, D.T. Tran, J. Lammertyn, Spherical nucleic acid enhanced FO-SPR DNA melting for detection of mutations in Legionella pneumophila, Anal. Chem. 85 (2013) 1734-1742.

[34] D. Daems, K. Knez, F. Delport, D. Spasic, J. Lammertyn, Real-time PCR melting analysis with fiber optic SPR enables multiplex DNA identification of bacteria, Analyst 141 (2016) 1906-1911.

[35] G. Polenta, S. Godefroy-Benrejeb, P. Delahaut, D. Weber, M. Abbott, Development of a competitive ELISA for the detection of Pecan (Carya illinoinensis (Wangenh.) K. Koch) traces in food, Food Anal. Methods 3 (2010) 375-381.

[36] G.G. Kock, Intraclass correlation coefficient, in: S. Kotz, N.L. Johnson (Eds.), Encyclopedia of Statistical Sciences, John Wiley and Sons, New York, 1982, pp. $213-217$.

[37] J. Pollet, F. Delport, K.P.F. Janssens, K. Jans, G. Maes, H. Pfeiffer, M. Wevers, J. Lammertyn, Fiber optic SPR biosensing of DNA hybridization and DNA protein interactions, Biosens. Bioelectron. 24 (2009) 864-869. 